\title{
Dopamine Axon Varicosities in the Prelimbic Division of the Rat Prefrontal Cortex Exhibit Sparse Immunoreactivity for the Dopamine Transporter
}

\author{
Susan R. Sesack,, ${ }^{1}$ Valerie A. Hawrylak, ${ }^{1}$ Claudia Matus, ${ }^{2}$ Margaret A. Guido, ${ }^{1}$ and Allan I. Levey ${ }^{3}$ \\ Departments of ${ }^{1}$ Neuroscience and Psychiatry, and ${ }^{2}$ Statistics, University of Pittsburgh, Pennsylvania 15260, and \\ ${ }^{3}$ Department of Neurology, Emory University, Atlanta, Georgia 30322
}

The dopamine transporter (DAT) critically regulates the duration of the cellular actions of dopamine and the extent to which dopamine diffuses in the extracellular space. We sought to determine whether the reportedly greater diffusion of dopamine in the rat prefrontal cortex (PFC) as compared with the striatum is associated with a more restricted axonal distribution of the cortical DAT protein. By light microscopy, avidin-biotin-peroxidase immunostaining for DAT was visualized in fibers that were densely distributed within the dorsolateral striatum and the superficial layers of the dorsal anterior cingulate cortex. In contrast, DAT-labeled axons were distributed only sparsely to the deep layers of the prelimbic cortex. By electron microscopy, DAT-immunoreactive profiles in the striatum and cingulate cortex included both varicose and intervaricose segments of axons. However, DAT-labeled processes in the prelimbic cortex were almost exclusively intervaricose axon segments. Immu- nolabeling for tyrosine hydroxylase in adjacent sections of the prelimbic cortex was localized to both varicosities and intervaricose segments of axons. These qualitative observations were supported by a quantitative assessment in which the diameter of immunoreactive profiles was used as a relative measure of whether varicose or intervaricose axon segments were labeled. These results suggest that considerable extracellular diffusion of dopamine in the prelimbic PFC may result, at least in part, from a paucity of DAT content in mesocortical dopamine axons, as well as a distribution of the DAT protein at a distance from synaptic release sites. The results further suggest that different populations of dopamine neurons selectively target the DAT to different subcellular locations.

Key words; cingulate cortex; dopamine; dopamine transporter; prefrontal cortex; prelimbic; striatum; tyrosine hydroxylase
The dopamine transporter (DAT) is a crucial protein in the regulation of dopamine transmission, serving to remove dopamine from the extracellular space after its release. Studies in animals lacking expression of the DAT gene (Giros et al., 1996) suggest that this protein is perhaps the single most important determinant of the extraneuronal concentration and duration of dopamine. The DAT is also a protein of considerable clinical significance. For example, psychostimulant drugs of abuse block or reverse the action of the DAT and increase dopamine levels in key forebrain regions (Moghaddam and Bunney, 1989; Kuhar et al., 1991; Giros et al., 1996). Furthermore, DAT content in the basal ganglia is reduced significantly during the normal course of aging (Bannon et al., 1992) and in patients with Parkinson's disease (Niznik et al., 1991; Harrington et al., 1996). The DAT also has been implicated as a potential site for uptake of environmental neurotoxins that might cause Parkinson's disease (Uhl, 1992), whereas low DAT levels may be associated with resistance to such lesions (Cerruti et al., 1993; Harrington et al., 1996).

Although the function of the DAT has been studied most extensively in the basal ganglia, the cortex also receives a significant dopamine innervation (Descarries et al., 1987; Berger et al.,

\footnotetext{
Received Aug. 15, 1997; revised Jan. 9, 1998; accepted Jan. 14, 1998.

We gratefully acknowledge the assistance of Drs. Allan Sampson and Satish Iyengar in statistical analysis and Drs. Deborah King and Holly Moore for editorial contributions. This work was supported by United States Public Health Service Grants MH50314, MH45156 (S.R.S.), and NS31937 (A.I.L.).

Correspondence should be addressed to Dr. Susan R. Sesack, Department of Neuroscience, 446 Crawford Hall, University of Pittsburgh, Pittsburgh, PA 15260. Copyright (C) 1998 Society for Neuroscience 0270-6474/98/182697-12\$05.00/0
}

1991) that is important for cognitive functioning (Brozoski et al., 1979; Simon et al., 1980). In the prelimbic division of the rat prefrontal cortex (PFC) (Krettek and Price, 1977), dopamine appears to undergo less regulation by DAT-mediated re-uptake when compared with the striatum, as evidenced by a greater extracellular diffusion distance (Garris et al., 1993; Garris and Wightman, 1994; Cass and Gerhardt, 1995). This difference may result simply from the lower dopamine innervation density in the mesocortical versus the nigrostriatal system. However, an alternative interpretation is that dopamine axons and varicosities in the prelimbic PFC have a lower content of DAT and, hence, a reduced uptake capacity. A similar hypothesis has been suggested for the ventral striatum, where there appear to be fewer dopamine uptake sites as compared with the dorsal striatum, despite a comparable innervation density (Marshall et al., 1990; Jones et al., 1996). Moreover, these observations are consistent with the lower immunoreactivity and mRNA signal for DAT in the ventral tegmental area (VTA) as compared with the substantia nigra (Shimada et al., 1992; Ciliax et al., 1995).

We sought to test the hypothesis that the neurochemical profile of dopamine overflow and diffusion in the rat prelimbic PFC is associated with a restricted distribution of the DAT protein within individual dopamine axons. We used an electron microscopic immunocytochemical approach to compare the distribution of DAT protein in the dorsolateral striatum and the deep layers of the prelimbic PFC. The relative specificity of the results obtained in the prelimbic cortex with DAT was assessed by comparison with another PFC region, the anterior cingulate cortex, the superficial layers of which are innervated by a separate 
Figure 1. Schematic drawings illustrating the regions sampled in coronal sections of rat forebrain. Shading indicates the approximate density of the dopamine innervation to the prelimbic division of the PFC $(P L)$, which is heaviest in layers $\mathrm{V}-\mathrm{VI}$, the rostral anterior cingulate cortex $(C I N G)$, which is most dense in layers I-III, and the corpus striatum (STR), which receives a dense dopamine input throughout its dorsoventral extent. The black trapezoids indicate the regions sampled by electron microscopy. These regions also are illustrated by light microscopy in Figure 3. $a c$, Anterior commissure; $c c$, corpus callosum.
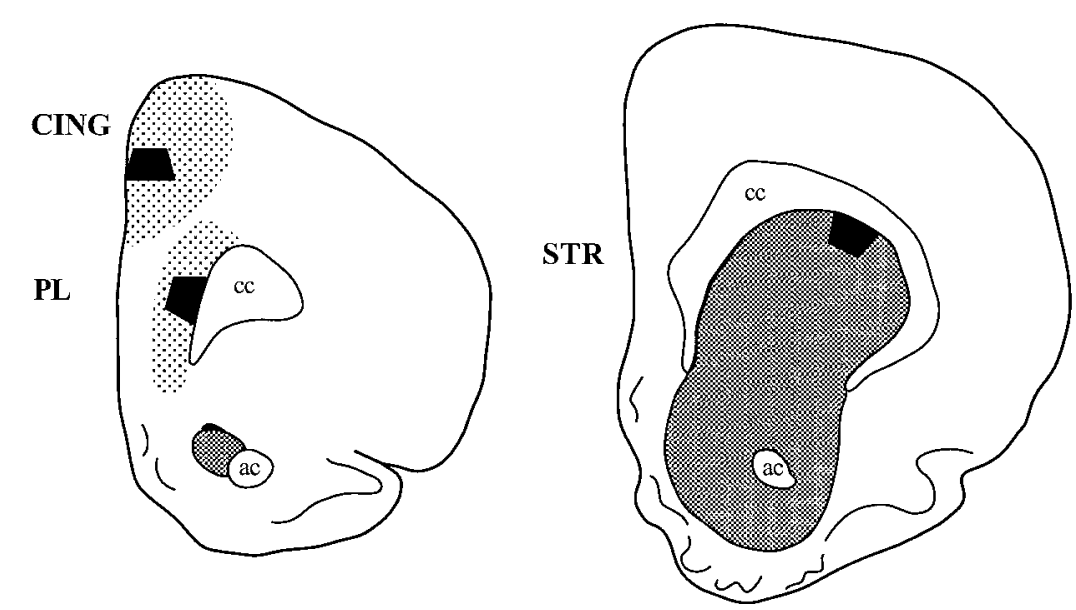

group of dopamine axons (Berger et al., 1991). Finally, as a positive procedural control, the distribution of immunoreactivity for DAT within the deep layers of the prelimbic PFC was compared in adjacent sections to the localization of another marker for dopamine axons, the catecholamine synthetic enzyme tyrosine hydroxylase $(\mathrm{TH})$.

Some of these data have been reported in preliminary form (Sesack et al., 1996).

\section{MATERIALS AND METHODS}

Immunocytochemistry. Eleven naive adult male Sprague Dawley rats were anesthetized deeply and perfused transcardially with $10 \mathrm{ml}$ of heparin saline $(1000 \mathrm{U} / \mathrm{ml})$, followed by fixative. For 10 rats, the fixative consisted of $50 \mathrm{ml}$ of $3.75 \%$ acrolein and $2 \%$ paraformaldehyde in $0.1 \mathrm{M}$ phosphate buffer, pH 7.4 (PB), followed by $250 \mathrm{ml}$ of $2 \%$ paraformaldehyde. To determine whether the degree of DAT immunostaining was dependent on the fixative that was used, we perfused the remaining animal with $500 \mathrm{ml}$ of $4 \%$ paraformaldehyde with $0.2 \%$ glutaraldehyde. The brains were removed, post-fixed in the final fixative for $30 \mathrm{~min}$, and sectioned at $50 \mu \mathrm{m}$ on a vibratome. To improve antigenicity and reduce nonspecific immunolabeling, we subsequently treated the sections for 30 min with $1 \%$ sodium borohydride (Leranth and Pickel, 1989) and rinsed them in PB. To reduce further the nonspecific labeling before incubation in primary antibody, we treated sections for $30 \mathrm{~min}$ in a blocking solution consisting of $1 \%$ bovine serum albumin and 3\% normal goat serum in 0.1 м Tris-buffered saline (TBS), $\mathrm{pH}$ 7.6. Sections for light microscopy were exposed to $0.4 \%$ Triton X-100 to enhance antibody penetration. Steps taken to enhance immunostaining for electron microscopy included the use of rapid freeze-thaw or $0.04 \%$ Triton X-100 and, in several experiments, two consecutive night incubations in primary antibody.

The qualitative assessment of DAT immunoreactivity was based on two different primary antibodies: rabbit polyclonal $(1: 100)$ and rat monoclonal (1:1000). Both antibodies were directed against the $\mathrm{N}$ terminus of the DAT protein (Ciliax et al., 1995; Hersch et al., 1997; Miller et al., 1997) and produced comparable immunocytochemical staining. However, only the rat monoclonal antibody was used in quantitative studies. The specificity of both antibodies was demonstrated by Western blot analysis against cloned transporter expressed in mammalian cells and against the native transporter expressed in brain. Interestingly, this analysis detected abundant DAT protein in the striatum but produced no detectable signal in the frontal cortex. This may have reflected the inclusion not only of the prelimbic and anterior cingulate cortices in the sample but of several cortical divisions that receive only a minor dopamine input (Hersch et al., 1997).

Additional tests for antibody specificity have included immunoprecipitation of digitonin-solubilized striatal DAT binding sites and loss of immunoreactivity in experimental animals after neurotoxic lesion with 6-hydroxydopamine (6-OHDA) or in postmortem human brain as a result of Parkinson's disease (Ciliax et al., 1995; Hersch et al., 1997; Miller et al., 1997). In a further control experiment for the present study the rat anti-DAT antibody was preadsorbed for $2 \mathrm{hr}$ with $100 \mu \mathrm{g} / \mathrm{ml}$ of the fusion protein antigen and then tested for immunocytochemical staining.
Because our pilot study found minimal immunoreactivity for DAT in the deep layers of the rat prelimbic PFC (Sesack et al., 1996), it became important to localize another marker for dopamine terminals in this region as a positive control for our immunolabeling procedure. To this end, adjacent sections through the prelimbic PFC of three animals were incubated in rabbit anti-TH antiserum (1:1000), obtained commercially from Eugene Tech (Ridgefield Park, NJ). The specificity of this antibody has been established in previous studies (Joh et al., 1973), and the relative selectivity of $\mathrm{TH}$ antisera for cortical dopamine axons, as opposed to norepinephrine fibers, has been documented extensively (Gaspar et al., 1989; Lewis and Sesack, 1997). We also have compared TH and dopamine immunolabeling directly in the prelimbic PFC of rats (Sesack et al., 1995), and our quantitative comparison revealed no difference in the synaptic contacts of these terminals. Furthermore, studies of dopamine $\beta$-hydroxylase or norepinephrine immunostaining in rat cortex report that few labeled varicosities form identifiable synapses (Descarries and Umbriaco, 1995; Branchereau et al., 1996), whereas the synaptic incidence for terminals immunolabeled for dopamine or $\mathrm{TH}$ is much higher (Van Eden et al., 1987; Séguéla et al., 1988; Descarries and Umbriaco, 1995; Sesack et al., 1995). Despite this difference in synaptic incidence, the relative size of dopamine versus norepinephrine varicosities is roughly equivalent (Descarries and Umbriaco, 1995). Thus, the $\mathrm{TH}$ antibodies that we used appear to label preferentially the dopamine terminals in the region that was examined (i.e., deep layers of the prelimbic cortex) where the dopamine innervation markedly exceeded that of norepinephrine (Berger et al., 1976; Lindvall and Björklund, 1984). Nevertheless, we cannot exclude the contribution of a few noradrenergic axons to the sample of TH-immunoreactive profiles.

Sections were incubated in primary antibody for $15 \mathrm{hr}$ at room temperature or for $40 \mathrm{hr}$ at $4^{\circ} \mathrm{C}$. The secondary antibodies used were biotinylated goat anti-rabbit IgG (1:400) or donkey anti-rat IgG (1:100). Avidin-biotin-peroxidase complex (Vectastain Elite, Vector Laboratories, Burlingame, CA) was applied at 1:200 (Hsu et al., 1981). The avidin-biotin-peroxidase immunostaining procedure was chosen because of its sensitivity for low-abundance antigens despite its relatively indiscrete subcellular localization (Hsu et al., 1981; Chan et al., 1990; Nirenberg et al., 1996). All incubations and rinses were performed in TBS with constant agitation. Bound peroxidase was visualized by the addition of $0.022 \% 3,3^{\prime}$-diaminobenzidine and $0.003 \% \mathrm{H}_{2} \mathrm{O}_{2}$ for $5 \mathrm{~min}$.

Sections for light microscopy were slide-mounted, dehydrated, and coverslipped. Sections for electron microscopy were post-fixed in $2 \%$ osmium tetroxide in $\mathrm{PB}$, dehydrated via increasing strengths of ethanol and propylene oxide, and plastic-embedded with Epon-812 (Electron Microscopy Sciences, Fort Washington, PA). Small regions within the cortex and striatum were cut from these thick sections and glued onto blocks of embedding plastic. The regions of interest were trimmed further (Fig. 1) and then sectioned at $60-70 \mathrm{~nm}$ on an ultramicrotome. The ultrathin sections were collected on copper mesh grids and stained with uranyl acetate and lead citrate before being viewed in a Zeiss 902 transmission electron microscope (Oberkochen, Germany).

Quantitative image analysis. The approximate density and morphological features of fibers immunoreactive for the DAT were assessed qualitatively, and a quantitative approach was used to further estimate the relative distribution of DAT protein to varicose or intervaricose seg- 
ments of axons. The quantitative assessment was based on the measurement of profile diameter, keeping in mind that, although diameter is not an index of morphology, small profiles have a greater probability of being axons, whereas large profiles have a greater probability of being varicosities.

The electron microscopic results from six rats with the best morphology and most robust staining with the rat anti-DAT antibody were quantified in three regions (Fig. 1): dorsolateral striatum, layers I-III of the rostral, dorsal anterior cingulate cortex, and layers V-VI of the prelimbic cortex (Krettek and Price, 1977). The cortical layers that were examined were chosen on the basis of the known distribution of dopamine fibers in the rat supragenual and pregenual mesocortical projections, respectively (Berger et al., 1991). For three of the six rats, adjacent thick sections through the prelimbic PFC were stained with rabbit anti-TH antibody and examined both qualitatively and quantitatively. The cingulate cortex was not included in this analysis of TH immunolabeling.

One to two thick tissue sections per region per animal were examined, and the surface of the tissue where antibody penetration was maximal was sampled at random. The specific immunoperoxidase reaction product for DAT was identified as an electron-dense flocculent precipitate that accumulated within the cytoplasm, along the inner plasmalemmal surface, and along the outer membranes of organelles, including synaptic vesicles. Such flocculent precipitate can be distinguished from other electron dense structures in the tissue, even when it is present at low levels (Sesack et al., 1994; Delle Donne et al., 1996, 1997). Furthermore, this flocculent product was not observed in presumed unlabeled structures in the immediately adjacent neuropil or in any structures viewed at greater depths from the surface.

At least 40 profiles immunoreactive for DAT (all regions) or $\mathrm{TH}$ (prelimbic cortex) were photographed at $13,000 \times$ and printed at $2.5 \times$ enlargement. Immunolabeled profiles were identified as varicose or intervaricose portions of axons (Peters et al., 1991) on the basis of their small size, location in fields of small unmyelinated axons, presence of synaptic vesicles, and/or occasional formation of synapses on spines or dendrites. Compared with intervaricose axon segments, varicosities were typically larger, contained more vesicles, and were more likely to form synapses. A few profiles contained small patches of weak immunoreaction product that were considered to be nonspecific. These profiles were excluded from analysis, as were densely immunolabeled profiles that did not have well delineated boundaries. The remaining profiles were numbered sequentially on the micrographs from upper left to lower right, and a random number generator was used to select 30 profiles per region per animal. This number of profiles was determined from a pilot study to be the minimum sample size per animal needed to detect a $30 \%$ difference among means between regions or markers with $80 \%$ power, using a Student's $t$ test. In total, 180 immunoreactive profiles per region for DAT and 90 profiles for TH in the prelimbic PFC were selected.

The electron micrographic negatives were scanned by a digital camera into an image analysis system (Advanced Imaging Concepts, Princeton, NJ). The immunoreactive processes were traced by a single investigator, and a set of rules was established to minimize variability in the tracing. For example, (1) when profiles were labeled heterogeneously, only the portions that contained immunoreaction product were traced; (2) when the plasma membrane was clearly visible, tracing was done directly along the membrane; (3) when the plasma membrane was obscured slightly by immunoreaction product or plane of section, tracing was done along the outer edge of the immunoreactivity; (4) when immunolabeled profiles were apposed to each other (primarily in the striatum), tracing was done along the inner edge of each apposed membrane so that the traced profiles did not merge.

An unbiased, computerized algorithm was used to determine the maximum diameter of each traced profile along its short axis by counting in one pixel layer at a time from the perimeter and forming a "topographic map" of the profile (Fig. 2). For immunoreactive profiles with eccentric shape, such as longitudinal sections through both varicose and intervaricose portions of an axon (e.g., Fig. $2 C$ ), this diameter measurement represented the most varicose portion of the profile. The data were analyzed statistically by a two-way ANOVA, with the main effects being either region and animal for DAT or marker and animal for DAT versus TH. The interactions between main effects were determined also, and post hoc analyses were performed with Tukey's studentized range test.

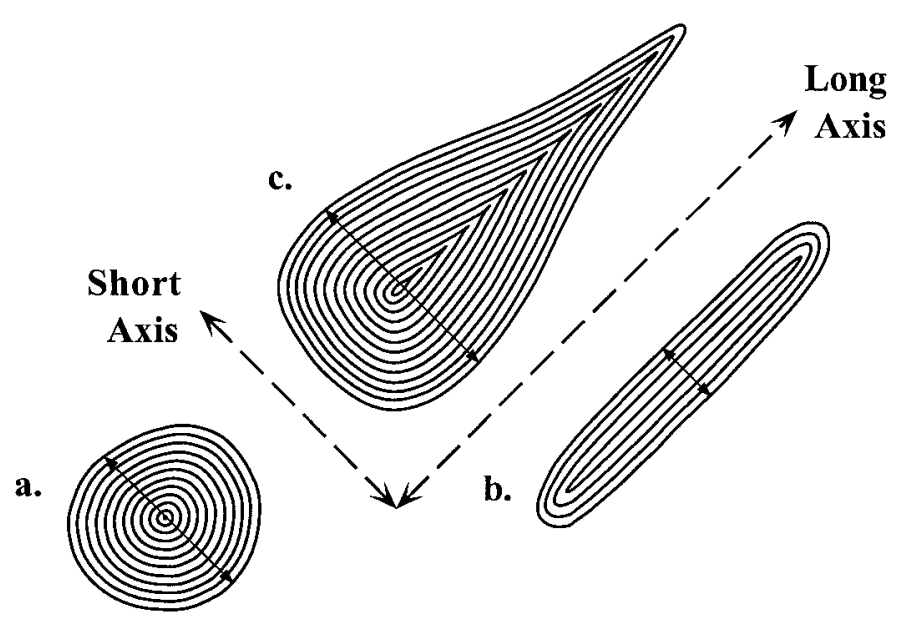

Figure 2. Schematic drawing illustrating the measurement of diameter after the perimeter of immunolabeled profiles has been traced. The representative profiles include $(a)$ a varicosity cut in cross section, $(b)$ a longitudinally sectioned axon, and $(c)$ an eccentrically shaped profile representing both varicose and intervaricose segments of an axon. In each case the number of pixel layers from the perimeter is counted until each counted pixel is bounded by other counted pixels. This represents the pixel radius, which is doubled to obtain the pixel diameter (arrows) and then converted to micrometers with a calibration. This dimension represents the maximal diameter through the short axis of each profile.

\section{RESULTS}

\section{Light microscopy}

Light microscopic examination of the dorsolateral striatum revealed immunoreactivity for DAT that was localized densely and diffusely to the neuropil surrounding unlabeled perikarya and bundles of myelinated axons (Fig. $3 A$ ). The density of the peroxidase reaction product precluded the visualization of individual fibers. Examination of the same striatal region in sections incubated in antibody preadsorbed with the DAT antigen revealed no detectable immunoreactivity (Fig. $3 B$ ).

In the rostral portion of the anterior cingulate cortex, DATimmunoreactive fibers were localized diff usely throughout layers I-III and often were clustered densely within layer III (Fig. 3C). DAT-immunoreactive axons in these clusters exhibited evidence of both branching and varicose beading. In the adjacent prelimbic division of the PFC, DAT-immunoreactive fibers were markedly sparse within the deep layers V-VI, even when the tissue was viewed with differential interference contrast (DIC) optics (Fig. $3 D$ ). A few of the DAT-immunoreactive axons were beaded or branched, whereas the remainder appeared to be fibers en passant. This weak immunolabeling in the prelimbic PFC was observed despite the use of two night incubations in primary antibody that contained a high concentration of detergent to enhance penetration. Furthermore, this low level of DAT immunoreactivity also was observed in the more ventral infralimbic division of the PFC, although this region was not explored further during this investigation.

\section{Electron microscopy}

By electron microscopic examination of the dorsolateral striatum, dense peroxidase immunoreactivity for the DAT was expressed abundantly in axon varicosities and preterminal axons (Fig. $4 \mathrm{~A}$ ) that exhibited features characteristic of dopamine fibers: lack of myelination, small size, content of mostly clear synaptic vesicles, and occasional formation in single sections of punctate symmetric synapses on spines or distal dendrites (Pickel et al., 1981; Bouyer 

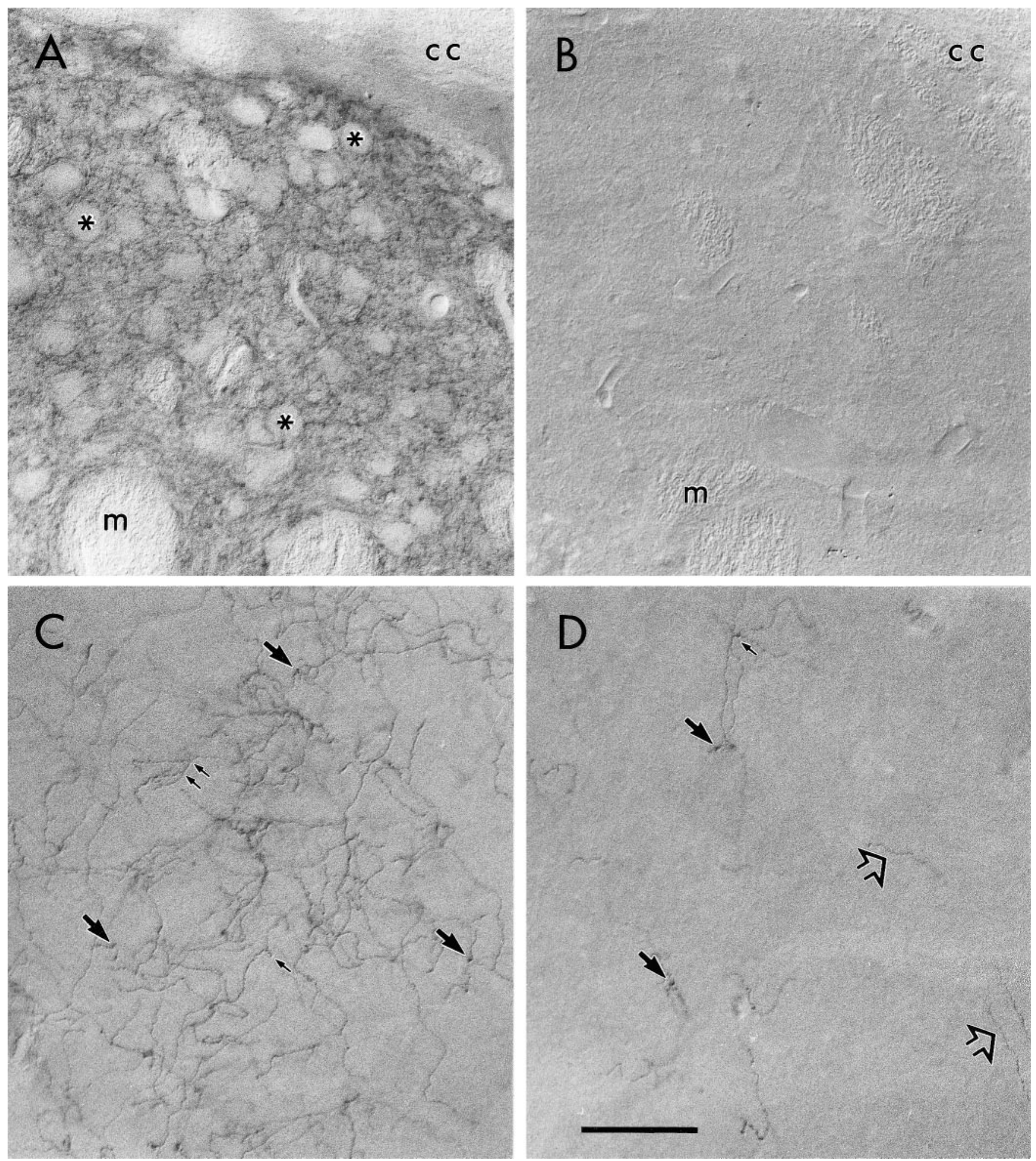

Figure 3. Light micrographs illustrating peroxidase immunoreactivity for DAT in the rat forebrain. $A$, In the dorsolateral striatum, dense peroxidase product for DAT is localized to the neuropil immediately beneath the corpus callosum $(\mathrm{cc}$ ). Perikarya (asterisks) and bundles of myelinated axons ( $m$ ) are unlabeled. $B$, No DAT immunoreactivity is detected in the same striatal region of sections incubated in primary antibody preadsorbed with the DAT antigen. $C$, In the rostral portion of the anterior cingulate cortex, a dense cluster of DAT-immunoreactive fibers is visualized in layer III. These presumed axons exhibit the branching (small arrows) and beading (large arrows) that are characteristic of terminal fibers. $D$, In layer VI of the prelimbic cortex from the same section as that shown in $C$, sparse fibers immunoreactive for DAT are observed. Although some are beaded or branched, others appear to be fibers of passage (open arrows) exiting the white matter. In $A-D$, up is dorsal and left is medial. Scale bar, $150 \mu \mathrm{m}$. 

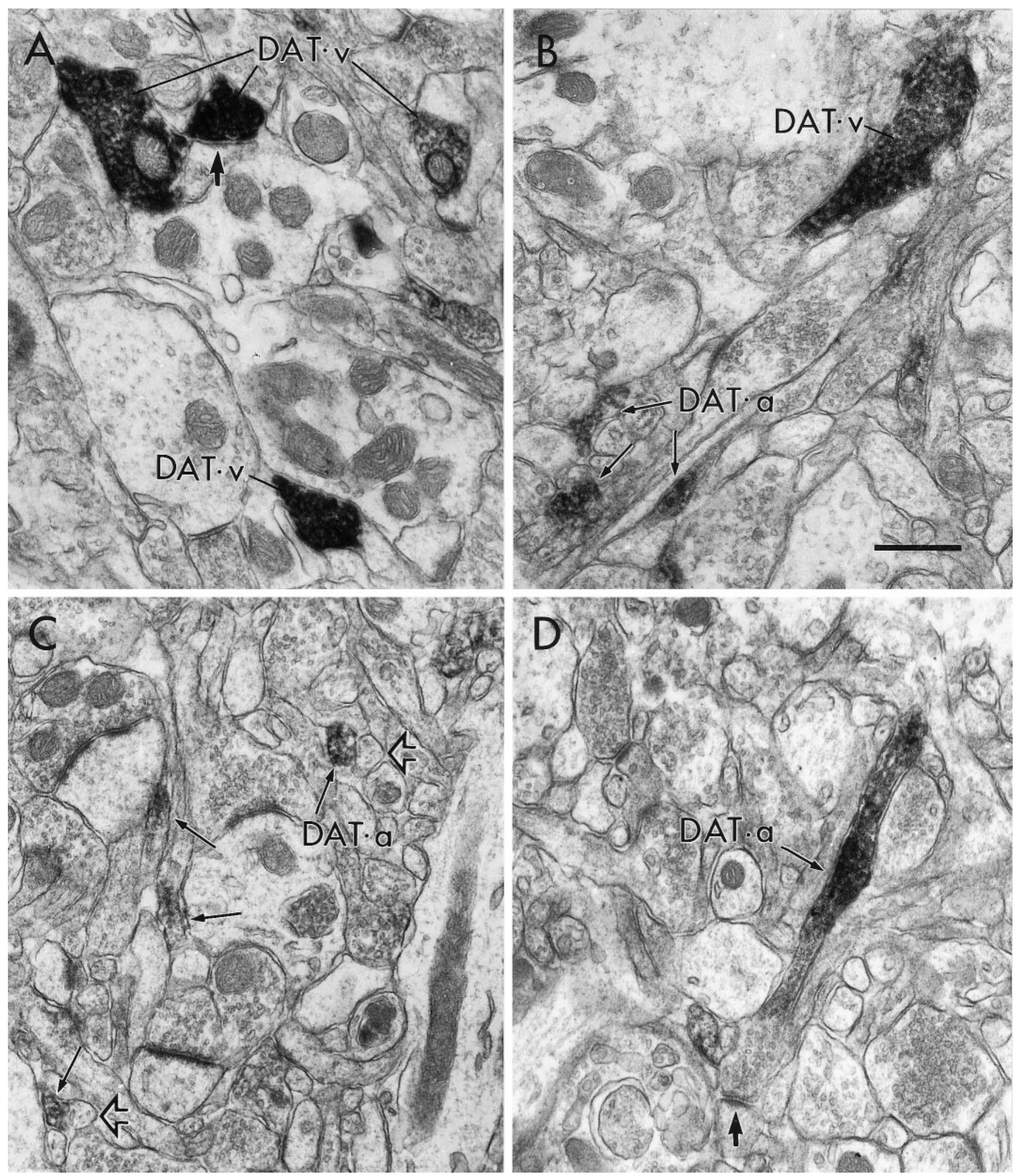

Figure 4. Electron micrographs illustrating peroxidase immunoreactivity for DAT in the rat forebrain. $A$, In the dorsolateral striatum, immunoreactivity for DAT is localized to axon varicosities $(D A T-v)$ that contain numerous synaptic vesicles surrounded by dense peroxidase product. One immunoreactive varicosity appears to form a small symmetric synapse on a dendritic process (thick arrow). $B$, In the cingulate cortex, DAT immunoreactivity is observed both in a varicose structure and in small axon-like profiles $(D A T$-a, thin arrows), some of which contain synaptic vesicles. $C$, In the prelimbic cortex, immunoreactivity for DAT is seen almost exclusively in small axon-like profiles (thin arrows). Immunonegative structures that exhibit similar size and morphology are indicated at the open arrows. D, DAT immunolabeling in the prelimbic cortex is visualized clearly in an axon cut longitudinally (thin arrow), whereas the contiguous varicosity forms a synapse on a dendritic spine (thick arrow) but otherwise is unlabeled for DAT. Scale bar, $0.5 \mu$ m. 


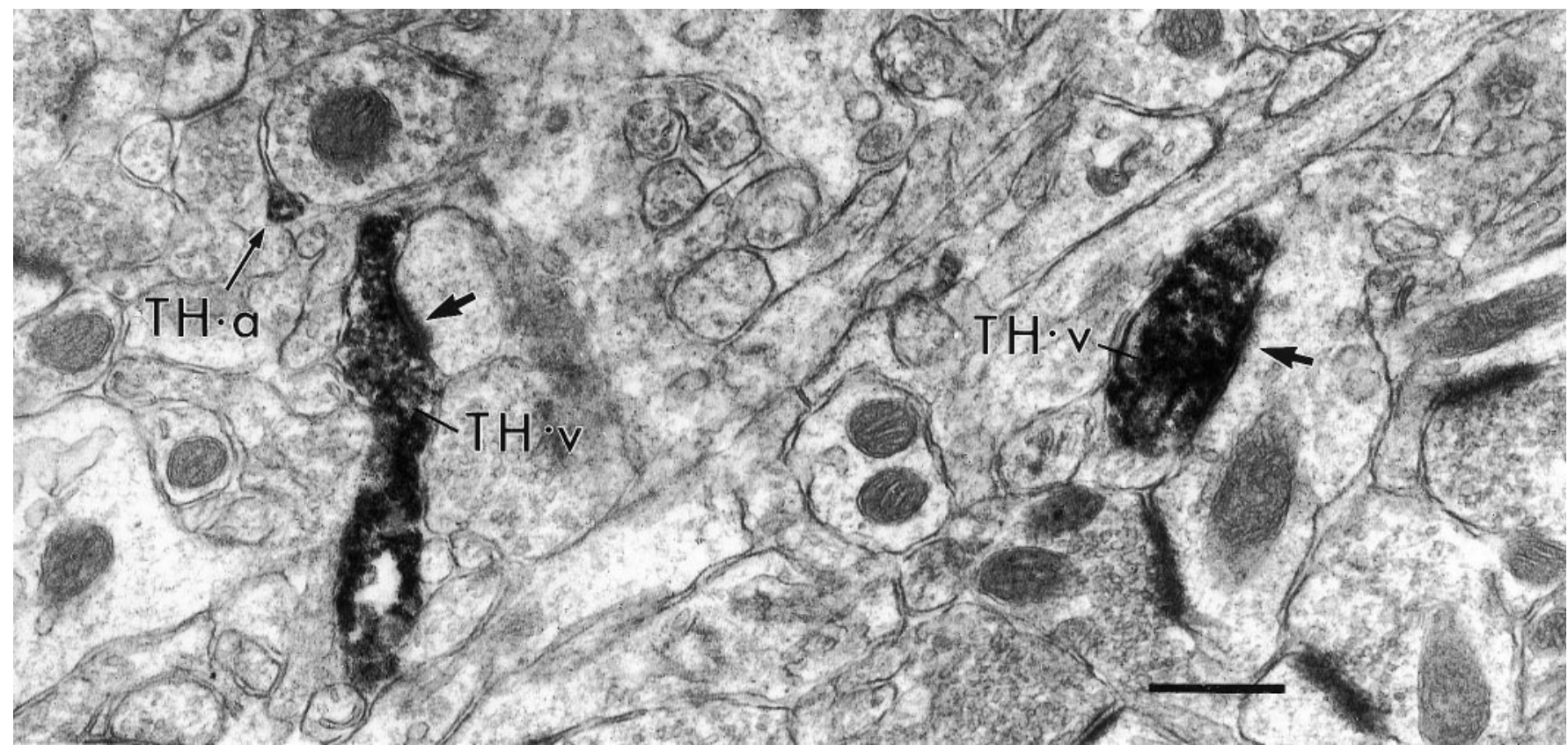

Figure 5. Electron micrographs illustrating peroxidase immunoreactivity for TH in the rat prelimbic PFC. In the deep layers of the prelimbic cortex, peroxidase immunoreactivity for TH was localized in axon varicosities $(T H-v)$ as well as in intervaricose axon segments (TH-a, thin arrow). The varicosities sometimes formed synapses on small dendrites (thick arrows). Scale bar, $0.5 \mu \mathrm{m}$.

et al., 1984; Freund et al., 1984; Descarries et al., 1996). In the superficial layers of the anterior cingulate cortex, similar immunoreactive profiles were observed. However, small-diameter vesicle-containing processes that probably represented intervaricose axon segments appeared qualitatively to contain a lower density of DAT immunoreactivity (Fig. 4B).

In the deep layers of the prelimbic PFC, peroxidase immunolabeling for the DAT was localized almost exclusively to the intervaricose segments of axons (Fig. $4 C, D$ ) and was qualitatively less dense than that observed in the dorsolateral striatum. Occasionally, immunoreactive axons were sectioned longitudinally, and it was possible to visualize the varicosities to which they gave rise. In such instances, the varicose portions of the axons invariably were devoid of DAT immunoreactivity, whereas the intervaricose regions contained a moderate density of peroxidase product (Fig. 4D). Consistent findings were obtained regardless of the fixative used, the primary antibody used (rat monoclonal, Fig. $4 C$ or rabbit polyclonal, Fig. $4 D$ ), the use of one or two night incubations in antibody, or the use of Triton X-100 detergent versus freeze-thaw to enhance antibody penetration. Peroxidase labeling in striatal and cortical sections virtually was eliminated by preadsorption of the primary antibody with the DAT antigen.

In adjacent sections of the prelimbic PFC, immunoreactivity for $\mathrm{TH}$ was detected in numerous axons and varicosities in the deep layers, some of which formed synapses on spines and small dendrites (Fig. 5).

\section{Quantitative analysis}

By quantitative analysis over all of the animals, the mean diameter $( \pm \mathrm{SD})$ of DAT-immunoreactive profiles was smaller in the prelimbic cortex $(0.137 \pm 0.049)$ than in the anterior cingulate cortex $(0.180 \pm 0.074)$ or the dorsolateral striatum $(0.218 \pm$ 0.084). Furthermore, this same pattern of mean diameter being smallest in the prelimbic cortex, larger in the cingulate cortex, and largest in the striatum was observed for each of the six animals. By two-way ANOVA, there was a significant overall effect of region $(p<0.0001)$ and no effect of animal. However, a significant interaction between region and animal $(p<0.012)$ suggested that some of the regional effect might be explained by animal differences. Because the region effects were similar for all animals, pairwise comparisons of main effects for regions were conducted with Tukey's studentized range test, with a simultaneous significance of $p<0.05$. All three regions were found to be significantly different from each other.

To explore further the nature of the interaction between region and animal, we did post hoc analyses with Tukey's procedure (again, with simultaneous significance of $p<0.05$ ) on all 18 animal-region comparisons. These comparisons revealed that a significant difference in diameter between the prelimbic cortex and the striatum occurred in all six animals. For the anterior cingulate cortex, significant differences with the prelimbic cortex were detected in three of the six animals and with the striatum in two of the six animals. However, it must be reemphasized that the same pattern of regional variation in mean diameter occurred for each animal, regardless of whether these differences reached statistical significance with the sample size chosen for this analysis.

Within the deep layers of the prelimbic PFC, DATimmunoreactive profiles were smaller in mean diameter than those labeled in adjacent sections for $\mathrm{TH}(0.215 \pm 0.088)$. By two-way ANOVA there was an overall significant effect of marker $(p<0.0001)$, with no effect of animal and no interaction effect.

In addition to the statistical analysis of means, it was considered useful to provide a full description of the data by using a frequency histogram of all 180 observations per region for DAT and all 90 observations for $\mathrm{TH}$ in the prelimbic PFC (Fig. 6). From this perspective a majority of DAT-immunoreactive profiles in the prelimbic cortex were of small diameter, whereas a greater proportion of DAT-immunoreactive profiles in the cingulate cor- 


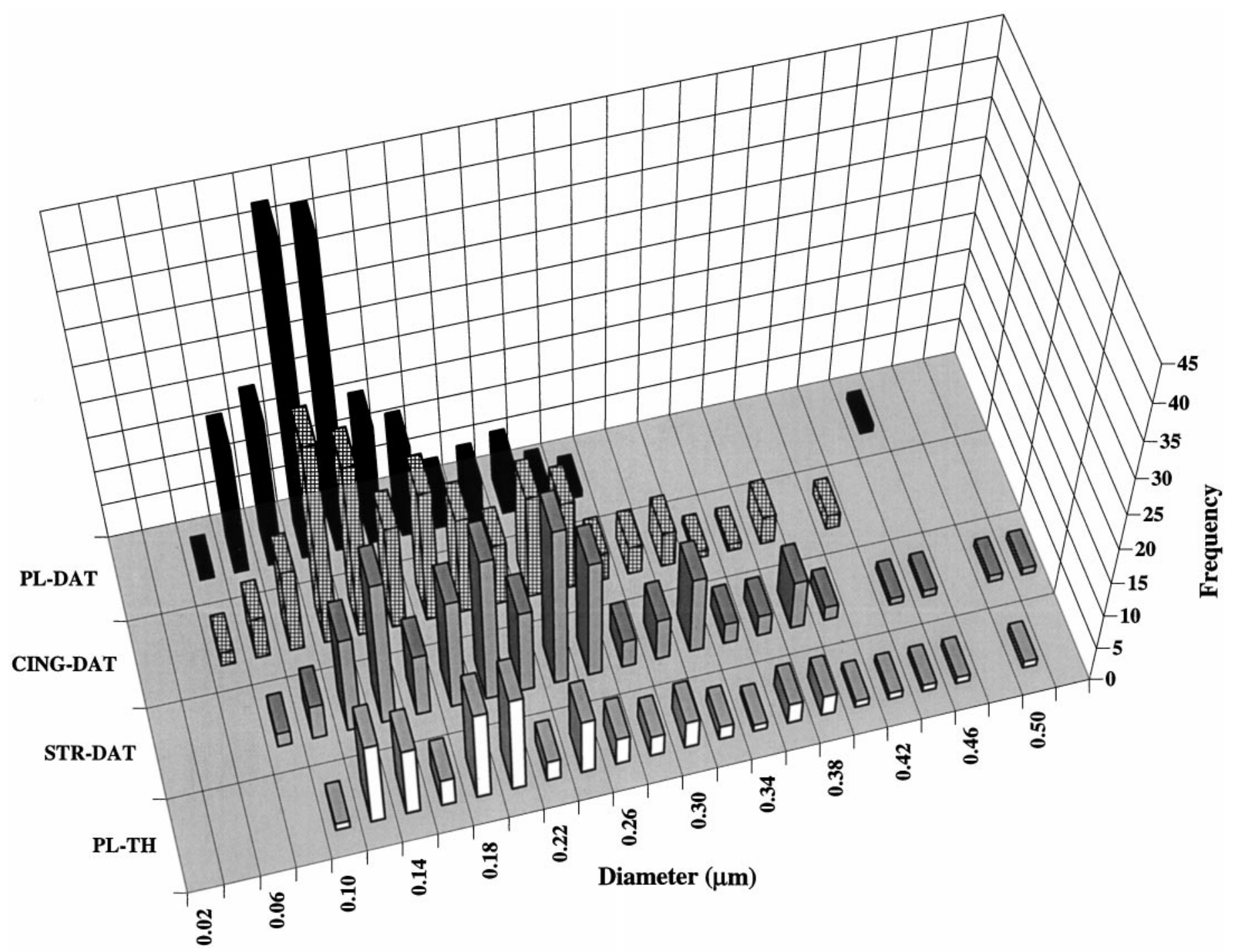

Figure 6. Histogram illustrating the frequency of diameters measured for profiles immunoreactive for DAT or TH in the rat forebrain. Each bar represents the total number (frequency) of profiles having a particular diameter that were immunoreactive for DAT in the prelimbic cortex (PL, black), anterior cingulate cortex (CING, hatched), or dorsolateral striatum (STR, gray) or for tyrosine hydroxylase in the prelimbic cortex (TH, white). For each region 30 profiles for each of six animals are represented in the case of DAT and for each of three animals in the case of TH. The histogram includes all of the raw data from which means and SD were calculated; see Results for the statistical analysis.

tex and striatum was of larger diameter. The latter was also true for TH-immunolabeled profiles in the prelimbic cortex.

In previous studies of dopamine axons in forebrain regions, profiles smaller than $0.2 \mu \mathrm{m}$ typically have been considered preterminal axons and often have been excluded from analysis of varicosities (Bouyer et al., 1984; Freund et al., 1984; Séguéla et al., 1988; Smiley and Goldman-Rakic, 1993; Descarries et al., 1996). Although we applied no such exclusion criterion to our analysis, it was of interest to determine the proportion of DATimmunoreactive profiles in the present study that had a diameter $\geq 0.2 \mu \mathrm{m}$. Across all of the animals, only $12 \%$ (range per animal, 3-20\%) of DAT-immunoreactive profiles in the prelimbic cortex met this criterion, whereas $35 \%$ (range, 17-53\%) of those in the cingulate cortex and $56 \%$ (range, $50-67 \%$ ) of those in the striatum were of this diameter or larger. Similarly, in the prelimbic cortex, $51 \%$ (range, 50-53\%) of profiles immunoreactive for $\mathrm{TH}$ were $\geq 0.2 \mu \mathrm{m}$ in diameter. These differences across regions and within the prelimbic PFC for the two markers were significantly different $(p<0.0001)$ by Fisher's exact test (Matthews and Farewell, 1996). Similar regional and marker differences were obtained when the criterion was set at 0.23 or $0.29 \mu \mathrm{m}$. In the latter case, only a single DAT-immunoreactive profile in the prelimbic PFC had a diameter that exceeded $0.29 \mu \mathrm{m}$.

\section{DISCUSSION}

The combined light and electron microscopic results suggest that dopamine axon varicosities in the rat prelimbic PFC express relatively low levels of DAT protein and a localization of DAT that is distant from synaptic release sites. These findings are consistent with observations of low DAT protein and mRNA in some VTA dopamine neurons and suggest that individual dopamine cells are capable of selectively targeting this important protein to different locations within the axon. Furthermore, the results agree with neurochemical studies reporting greater extracellular diffusion of dopamine in the prelimbic PFC as compared with the dorsal striatum. Although the data appear to support a 


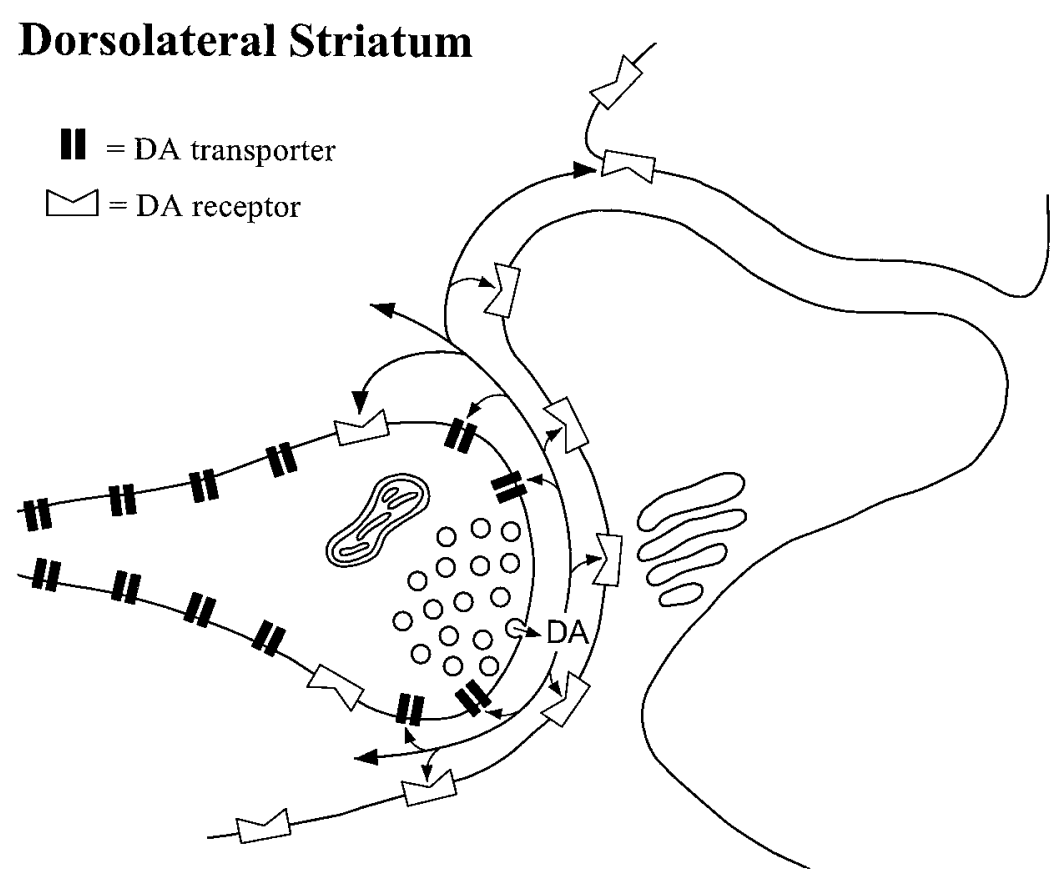

Figure 7. Schematic diagrams illustrating the putative distribution of DAT proteins in the dorsolateral striatum and prelimbic cortex. In the striatum, dopamine released at synaptic sites is subject to extensive re-uptake by DAT localized to the plasma membrane adjacent to the presynaptic zone and along preterminal portions of these axons. In the prelimbic PFC, evidence for perisynaptic DAT is lacking, although a low density of DAT protein is observed along preterminal portions of presumed dopamine axons. Thus, synaptically released dopamine is subject to less extensive uptake and greater extracellular diffusion. The functional impact of this extracellular dopamine may be limited by the low density of receptors for dopamine, which are substantially less abundant in the cortex than in the striatum.

\section{Prelimbic Cortex}

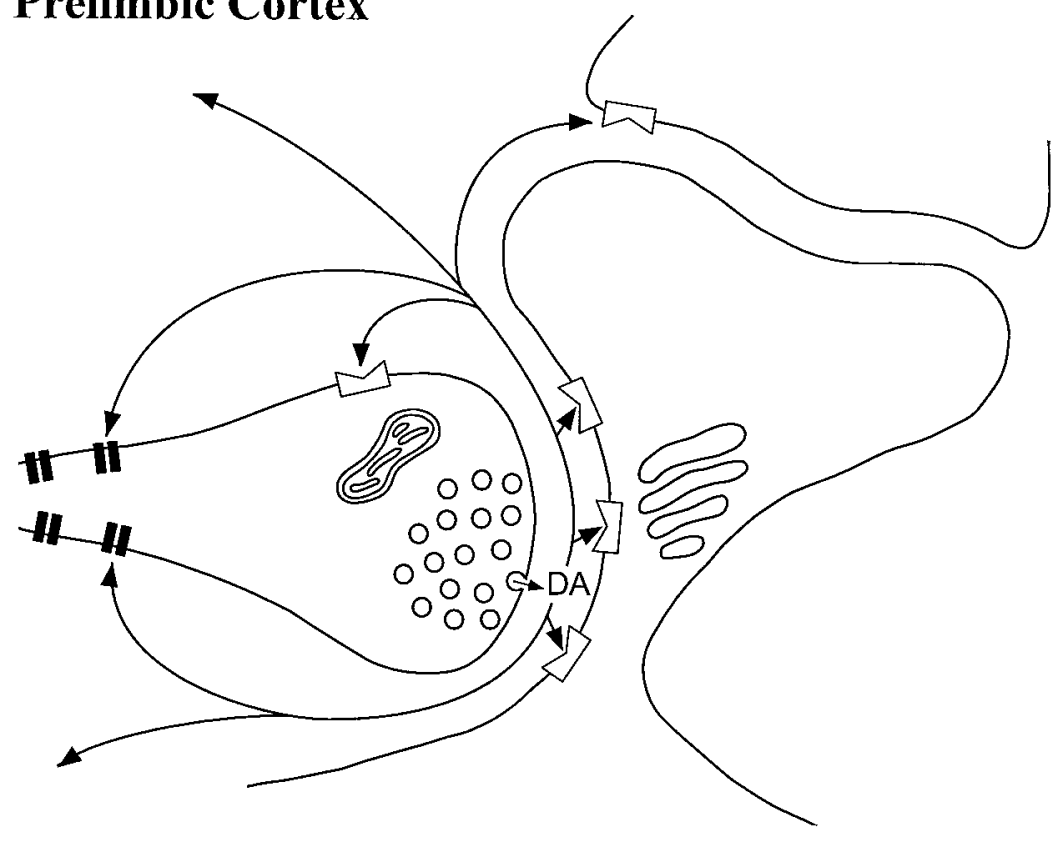

greater paracrine role for cortical dopamine, the actual sphere of influence of dopamine in the PFC may be limited by the low density of its receptors. These observations and hypotheses are depicted schematically in Figure 7.

\section{Methodology and comparison to published findings} Light microscopy

The present light microscopic distribution of DAT compares well with previous immunocytochemical studies showing a dense localization to the striatum and weaker labeling of cortex (Ciliax et al., 1995; Freed et al., 1995; Nirenberg et al., 1996). However, the cortical pattern of DAT labeling does not match previous accounts of dopamine axons that used other markers (Descarries et al., 1987; Van Eden et al., 1987; Séguéla et al., 1988; Berger et al., 1991). Although the distribution of DAT in the superficial layers of the anterior cingulate cortex matches the innervation by dopamine axons, the DAT fiber density in the deep layers of the prelimbic and infralimbic cortices underestimates the known distribution of dopamine axons in these areas. These observations are supported by biochemical reports of low DAT protein levels in the medial PFC (Vaughan et al., 1996) and by autoradiographic studies describing fewer DAT sites in the deep layers of the prelimbic cortex versus the cingulate cortex or subcortical sites [Scatton et al. (1985); Coulter et al. (1995); but see Descarries et al. (1987)]. These findings suggest that the density of DAT in 
terminal regions reflects differences in the dopamine cells of origin, because the superficial layers are innervated by the substantia nigra whereas the deep layer input derives from the VTA (Berger et al., 1991).

The potential contribution of technical factors to the sparsity of DAT in the prelimbic PFC seems unlikely, because the antibody incubation conditions produced robust labeling of the striatum and adjacent cingulate cortex in the same animals. It is possible that the dopamine neurons projecting to the prelimbic PFC express a different transporter gene product. However, a second DAT gene has not yet been identified (Uhl, 1992; Lorang et al., 1994; Bannon et al., 1995). Moreover, recent biochemical evidence suggests that the DAT protein in the striatum, accumbens, PFC, and midbrain is the product of a single gene (Vaughan et al., 1996). Alternatively, the DAT in mesoprefrontal dopamine neurons may be modified biochemically after translation in a manner that prevents antibody recognition. For example, differences in phosphorylation or glycosylation of the DAT (Lew et al., 1992; Vaughan et al., 1996; Huff et al., 1997) might alter both function and antibody binding. However, to date, neither phosphorylation nor glycosylation has been shown to alter recognition by DAT antibodies directed against four different epitopes (Patel et al., 1994; Vaughan et al., 1996; Huff et al., 1997).

Perhaps the most parsimonious explanation for the sparse distribution of DAT immunoreactivity in the prelimbic PFC is the presence of dopamine axons, for which the content of DAT protein is below detectable levels. This suggestion is consistent with reports of neurons that express mRNA for TH, but not DAT (Augood et al., 1993; Lorang et al., 1994), in the medial VTA regions that project to the prelimbic PFC (Swanson, 1982; Berger et al., 1991). A similar observation also has been made in the primate VTA (Haber et al., 1995). Immunoreactivity for the DAT is also weak in the medial VTA (Ciliax et al., 1995), suggesting that reduced somatodendritic localization of DAT protein accompanies sparse levels of DAT in axons. Low levels of DAT also have been reported in the dopamine neurons of the hypothalamus, retina, and olfactory bulb (Shimada et al., 1992; Cerruti et al., 1993; Lorang et al., 1994; Ciliax et al., 1995). Moreover, our results are consistent with a preliminary report that some cortical serotonin axons lack immunoreactivity for the serotonin transporter (Axt et al., 1995).

\section{Electron microscopy}

In the present study the ultrastructural features of varicosities labeled for DAT in the striatum and cingulate cortex match those previously described with uptake of radiolabeled transmitter (Descarries et al., 1987) or antibodies against DAT (Nirenberg et al., 1996; Hersch et al., 1997), dopamine (Descarries et al., 1996), or TH (Pickel et al., 1981; Bouyer et al., 1984; Freund et al., 1984). However, in the prelimbic PFC the almost exclusive distribution of DAT to small-diameter intervaricose axon segments is discrepant with other markers of dopamine fibers (listed above), which frequently label varicosities as well as the intervaricose portions of axons (Descarries et al., 1987; Van Eden et al., 1987; Séguéla et al., 1988; Sesack et al., 1995).

Although the use of heavy metal counterstaining may have prevented the detection of low levels of immunoperoxidase product for DAT in the prelimbic PFC, the observation in longitudinal sections that the varicose portions of otherwise immunoreactive axons contained no detectable DAT labeling argues that technical factors did not contribute significantly to the ultrastructural findings. It also should be noted that the failure to localize DAT to varicosities within the prelimbic PFC occurred despite the use of the sensitive avidin-biotin immunoperoxidase method (Hsu et al., 1981) and the ability of peroxidase product to diffuse short distances within labeled structures (Courtoy et al., 1983). Although immunogold methods provide better subcellular localization and have been used to demonstrate a perisynaptic localization of DAT in the striatum (Nirenberg et al., 1996; Hersch et al., 1997), these approaches were not chosen for the present study because of their low sensitivity (Chan et al., 1990).

The distribution of DAT to intervaricose axon segments in the prelimbic PFC suggests that this protein is localized primarily at a distance from varicose sites of release. However, dopamine axons in the striatum sometimes exhibit synapses along intervaricose regions (Freund et al., 1984; Groves et al., 1994). Although we have not observed such occurrences in our cortical studies and none has been reported to date in the rodent or primate PFC (Séguéla et al., 1988; Smiley and Goldman-Rakic, 1993), a complete serial reconstruction of dopamine axons is required to address this issue fully. Furthermore, the widely held view that transmitter release occurs via vesicle exocytosis at active zones has not been proven conclusively in the CNS (Smith and Augustine, 1988). Thus, the exact spatial relationship between sites of dopamine release and re-uptake in individual cortical axons remains to be determined.

\section{Functional implications}

Several neurochemical observations are consistent with the observed paucity of DAT in the rat prelimbic PFC. For example, both endogenously released (Garris et al., 1993; Garris and Wightman, 1994) and exogenously applied (Cass and Gerhardt, 1995; Lee et al., 1996) dopamine exhibit greater extracellular diff usion and slower clearance in the PFC as compared with other forebrain areas. Although a direct comparison between the prelimbic and anterior cingulate cortices has not been made, Garris and colleagues (1993) did show that electrical stimulation evoked a voltammetric signal for dopamine only in the ventral, and not the dorsal, region of the anteromedial cortex. Investigators also have noted that the ratio of dopamine in dialysate to whole tissue levels is considerably higher in the PFC than in the striatum or nucleus accumbens, suggesting that the cortex expresses a proportionally greater amount of extracellular dopamine relative to intraneuronal stores (Sharp et al., 1986; Maisonneuve et al., 1990; Garris et al., 1993).

There are several potential explanations for these findings. Compared with other forebrain dopamine systems, mesocortical dopamine neurons may have a greater capacity for release (Sharp et al., 1986; Hoffman et al., 1988; Garris et al., 1993), consistent with their higher firing rates, more efficient depolarization-release coupling, and absence of autoreceptor inhibition of synthesis (Chiodo et al., 1984; White and Wang, 1984; Wolf et al., 1986; Hoffman et al., 1988). Other contributing factors could include variations in the levels of metabolic enzymes or extracellular tortuosity factors that affect diffusion (Nicholson, 1995). However, studies in mice lacking DAT gene expression (Giros et al., 1996) suggest that dopamine synthesis, autoreceptor density, and other factors have less impact on extracellular dopamine than has the DAT protein itself. Thus, the sparsity of DAT in the PFC might contribute to higher extracellular levels, as compared with the striatum, if each cortical dopamine axon contains proportionally less DAT protein and/or if the DAT is localized further from the release sites. 
Other findings that support this view include the reportedly reduced efficacy of selective dopamine uptake blockers in the PFC as compared with subcortical regions (Carboni et al., 1990; Cenci et al., 1992; Pozzi et al., 1994). Cocaine is also less potent at blocking dopamine uptake into synaptosomes or tissue slices from the PFC than those from the striatum (Hadfield and Nugent, 1983; Izenwasser et al., 1990; Elsworth et al., 1993). Furthermore, at all systemic doses, cocaine produces a less profound increase in extracellular dopamine in the PFC than in the striatum (Moghaddam and Bunney, 1989).

Despite the paucity of DAT in the prelimbic PFC, additional mechanisms do exist to terminate the actions of dopamine, including diffusion, extraneuronal metabolism (Sharp et al., 1986; Maisonneuve et al., 1990; Karoum et al., 1994), and uptake by proteins other than the DAT. Of particular note, dopamine is the preferred substrate for the norepinephrine transporter (NET) (Bannon et al., 1995), and dopamine is known to be taken up into norepinephrine axons in the PFC (Carboni et al., 1990; Izenwasser et al., 1990; Elsworth et al., 1993; Pozzi et al., 1994; Tanda et al., 1994; Gresch et al., 1995; Lee et al., 1996). On the basis of these observations it has been suggested that the clinical actions of antidepressant drugs that block the NET may include an increase in dopamine levels in the PFC (Carboni et al., 1990; Pozzi et al., 1994; Tanda et al., 1994). However, despite the availability of this mechanism, the PFC still exhibits a reduced capacity for dopamine clearance (Garris et al., 1993; Garris and Wightman, 1994; Cass and Gerhardt, 1995), perhaps because of the sparsity of norepinephrine terminals in the deep layers of the prelimbic PFC (Berger et al., 1976; Lindvall and Björklund, 1984). In support of this suggestion, the NET appears to play a greater role in clearing exogenously applied dopamine in the dorsal (i.e., cingulate) than in the ventral (i.e., prelimbic) PFC (Cass and Gerhardt, 1995).

\section{Conclusions}

It has been argued that dopamine primarily serves a paracrine role in the PFC (Garris and Wightman, 1994), although other observations argue against this hypothesis. First, as discussed above, there are multiple mechanisms for dopamine clearance in the cortex, including the sparse DAT protein that is present. Second, a significant number of dopamine varicosities form conventional synapses in both the rat (Séguéla et al., 1988) and monkey (Smiley and Goldman-Rakic, 1993; Sesack et al., 1995) PFC and exhibit specificity in their synaptic targets (Lewis et al., 1996). Finally, overall dopamine receptor expression is substantially lower in the cortex, as compared with the striatum, and many dopamine receptor subtypes exhibit specificity in their neuronal distribution (Levey et al., 1993; Bergson et al., 1995; Gaspar et al., 1995; Mrzljak et al., 1996). Such a profile would not be predicted for a transmitter with widely distributed actions on multiple cell types.

An alternative hypothesis is that synaptically released dopamine produces the greatest functional impact, with additional extrasynaptic actions occurring only over short distances. Establishing the validity of this hypothesis will require exact knowledge about the concentration gradients of extracellular dopamine and the location and affinity of receptors relative to release sites. However, if this speculation has credence, it suggests that mesoprefrontal dopamine neurons may express little DAT protein because it is not critical for terminating the actions of dopamine and because it is economical to avoid the energy-requiring process of re-uptake.

\section{REFERENCES}

Augood SJ, Westmore K, McKenna PJ, Emson PC (1993) Co-expression of dopamine transporter mRNA and tyrosine hydroxylase mRNA in ventral mesencephalic neurones. Mol Brain Res 20:328-334.

Axt KJ, Molliver ME, Qian Y, Blakely RD (1995) Subtypes of 5-HT axons differ in their expression of serotonin transporter. Soc Neurosci Abstr 21:865.

Bannon MJ, Poosch MS, Xia Y, Goebel DJ, Cassin B, Kapatos G (1992) Dopamine transporter mRNA content in human substantia nigra decreases precipitously with age. Proc Natl Acad Sci USA 89:7095-7099.

Bannon MJ, Granneman JG, Kapatos G (1995) The dopamine transporter: potential involvement in neuropsychiatric disorders. In: Psychopharmacology: the fourth generation of progress (Bloom FE, Kupfer DJ, eds), pp 179-187. New York: Raven.

Berger B, Thierry AM, Tassin JP, Moyne MA (1976) Dopaminergic innervation of the rat prefrontal cortex: a fluorescence histochemical study. Brain Res 106:133-145.

Berger B, Gaspar P, Verney C (1991) Dopaminergic innervation of the cerebral cortex: unexpected differences between rodents and primates. Trends Neurosci 14:21-27.

Bergson C, Mrzljak L, Smiley JF, Pappy M, Levenson R, Goldman-Rakic PS (1995) Regional, cellular, and subcellular variations in the distribution of $D_{1}$ and $D_{5}$ receptors in primate brain. $J$ Neurosci 15:7821-7836.

Bouyer JJ, Joh TH, Pickel VM (1984) Ultrastructural localization of tyrosine hydroxylase in rat nucleus accumbens. J Comp Neurol 227:92-103.

Branchereau P, Van Bockstaele EJ, Chan J, Pickel VM (1996) Pyramidal neurons in rat prefrontal cortex show a complex synaptic response to single electrical stimulation of the locus coeruleus region: evidence for antidromic activation and GABAergic inhibition using in vivo intracellular recording and electron microscopy. Synapse 22:313-331.

Brozoski TJ, Brown RM, Rosvold HE, Goldman PS (1979) Cognitive deficit caused by regional depletion of dopamine in prefrontal cortex of rhesus monkey. Science 205:929-932.

Carboni E, Tanda GL, Frau R, Di Chiara G (1990) Blockade of the noradrenaline carrier increases extracellular dopamine concentrations in the prefrontal cortex: evidence that dopamine is taken up in vivo by noradrenergic terminals. J Neurochem 55:1067-1070.

Cass WA, Gerhardt GA (1995) In vivo assessment of dopamine uptake in rat medial prefrontal cortex: comparison with dorsal striatum and nucleus accumbens. J Neurochem 65:201-207.

Cenci MA, Kalén P, Mandel RJ, Björklund A (1992) Regional differences in the regulation of dopamine and noradrenaline release in medial frontal cortex, nucleus accumbens, and caudate-putamen: a microdialysis study in the rat. Brain Res 581:217-228.

Cerruti C, Walther DM, Kuhar MJ, Uhl GR (1993) Dopamine transporter mRNA expression is intense in rat midbrain neurons and modest outside midbrain. Mol Brain Res 18:181-186.

Chan J, Aoki C, Pickel VM (1990) Optimization of differential immunogold-silver and peroxidase labeling with maintenance of ultrastructure in brain sections before plastic embedding. J Neurosci Methods 33:113-127.

Chiodo LA, Bannon MJ, Grace AA, Roth RH, Bunney BS (1984) Evidence for the absence of impulse-regulating somatodendritic and synthesis-modulating nerve terminal autoreceptors on subpopulations of mesocortical dopamine neurons. Neuroscience 12:1-16.

Ciliax BJ, Heilman C, Demchyshyn LL, Pristupa ZB, Ince E, Hersch SM, Niznik HB, Levey AI (1995) The dopamine transporter: immunocytochemical characterization and localization in brain. J Neurosci 15:1714-1723.

Coulter CL, Happe HK, Bergman DA, Murrin LC (1995) Localization and quantification of the dopamine transporter: comparison of $\left[{ }^{3} \mathrm{H}\right.$ ]WIN 35,428 and [ ${ }^{125}$ I]RTI-55. Brain Res 690:217-224.

Courtoy PJ, Picton DH, Farquhar MG (1983) Resolution and limitations of the immunoperoxidase procedure in the localization of extracellular matrix antigens. J Histochem Cytochem 31:945-951.

Delle Donne KT, Sesack SR, Pickel VM (1996) Ultrastructural immunocytochemical localization of neurotensin and the dopamine $\mathrm{D}_{2}$ receptor in the rat nucleus accumbens. J Comp Neurol 371:552-566.

Delle Donne KT, Sesack SR, Pickel VM (1997) Ultrastructural immu- 
nocytochemical localization of the dopamine $\mathrm{D}_{2}$ receptor within GABAergic neurons of the rat striatum. Brain Res 746:239-255.

Descarries L, Umbriaco D (1995) Ultrastructural basis of monoamine and acetylcholine function in CNS. Semin Neurosci 7:309-318.

Descarries L, Lemay B, Doucet G, Berger B (1987) Regional and laminar density of the dopamine innervation in adult rat cerebral cortex. Neuroscience 21:807-824.

Descarries L, Watkins KC, Garcia S, Bosler O, Doucet G (1996) Dual character, asynaptic and synaptic, of the dopamine innervation in adult rat neostriatum: a quantitative autoradiographic and immunocytochemical analysis. J Comp Neurol 375:167-186.

Elsworth JD, Taylor JR, Berger P, Roth RH (1993) Cocaine-sensitive and -insensitive dopamine uptake in prefrontal cortex, nucleus accumbens, and striatum. Neurochem Int 23:61-69.

Freed C, Revay R, Vaughan RA, Kriek E, Grant S, Uhl GR, Kuhar MJ (1995) Dopamine transporter immunoreactivity in rat brain. J Comp Neurol 359:340-349.

Freund TF, Powell JF, Smith AD (1984) Tyrosine hydroxylaseimmunoreactive boutons in synaptic contact with identified striatonigral neurons, with particular reference to dendritic spines. Neuroscience 13:1189-1215.

Garris PA, Wightman RM (1994) Different kinetics govern dopaminergic transmission in the amygdala, prefrontal cortex, and striatum: an in vivo voltammetric study. J Neurosci 14:442-450.

Garris PA, Collins LB, Jones SR, Wightman RM (1993) Evoked extracellular dopamine in vivo in the medial prefrontal cortex. J Neurochem 61:637-647.

Gaspar P, Berger B, Febvret A, Vigny A, Henry JP (1989) Catecholamine innervation of the human cerebral cortex as revealed by comparative immunohistochemistry of tyrosine hydroxylase and dopaminebeta-hydroxylase. J Comp Neurol 279:249-271.

Gaspar P, Bloch B, Le Moine C (1995) $\mathrm{D}_{1}$ and $\mathrm{D}_{2}$ receptor gene expression in the rat frontal cortex: cellular localization in different classes of efferent neurons. Eur J Neurosci 7:1050-1063.

Giros B, Jaber M, Jones SR, Wightman RM, Caron MG (1996) Hyperlocomotion and indifference to cocaine and amphetamine in mice lacking the dopamine transporter. Nature 379:606-612.

Gresch PJ, Sved AF, Zigmond MJ, Finlay JM (1995) Local influence of endogenous norepinephrine on extracellular dopamine in rat medial prefrontal cortex. J Neurochem 65:111-116.

Groves PM, Linder JC, Young SJ (1994) 5-Hydroxydopamine-labeled dopaminergic axons: three-dimensional reconstructions of axons, synapses, and postsynaptic targets in rat neostriatum. Neuroscience 58:593-604.

Haber SN, Ryoo H, Cox C, Lu W (1995) Subsets of midbrain dopaminergic neurons in monkeys are distinguished by different levels of mRNA for the dopamine transporter: comparison with the mRNA for the $\mathrm{D}_{2}$ receptor, tyrosine hydroxylase, and calbindin immunoreactivity. J Comp Neurol 362:400-410.

Hadfield MG, Nugent EA (1983) Cocaine: comparative effect on dopamine uptake in extrapyramidal and limbic systems. Biochem Pharmacol 32:744-746.

Harrington KA, Augood SJ, Kingsbury AE, Foster OJF, Emson PC (1996) Dopamine transporter (DAT) and synaptic vesicle amine transporter (VMAT2) gene expression in the substantia nigra of control and Parkinson's disease. Mol Brain Res 36:157-162.

Hersch SM, Yi H, Heilman CJ, Edwards RH, Levey AI (1997) Subcellular localization and molecular topology of the dopamine transporter in the striatum and substantia nigra. J Comp Neurol 388:211-227.

Hoffman IS, Talmaciu RK, Ferro CP, Cubeddu LX (1988) Sustained high release at rapid stimulation rates and reduced functional autoreceptors characterize prefrontal cortex dopamine terminals. J Pharmacol Exp Ther 245:761-772.

Hsu S-M, Raine L, Fanger H (1981) Use of avidin-biotin-peroxidase complex $(\mathrm{ABC})$ in immunoperoxidase techniques: a comparison between $\mathrm{ABC}$ and unlabeled antibody (PAP) procedures. J Histochem Cytochem 29:577-580.

Huff RA, Vaughan RA, Kuhar MJ, Uhl GR (1997) Phorbol esters increase dopamine transporter phosphorylation and decrease transport $V_{\text {max }}$. J Neurochem 68:225-232.

Izenwasser S, Werling LL, Cox BM (1990) Comparison of the effects of cocaine and other inhibitors of dopamine uptake in rat striatum, nucleus accumbens, olfactory tubercle, and medial prefrontal cortex. Brain Res 520:303-309.

Joh TH, Gegham C, Reis DJ (1973) Immunocytochemical demonstra- tion of increased tyrosine hydroxylase protein in sympathetic ganglia and adrenal medulla elicited by reserpine. Proc Natl Acad Sci USA 70:2767-2771.

Jones SR, O’Dell SJ, Marshall JF, Wightman RM (1996) Functional and anatomical evidence for different dopamine dynamics in the core and shell of the nucleus accumbens in slices of rat brain. Synapse 23:224-231.

Karoum F, Chrapusta SJ, Egan MF (1994) 3-Methoxytyramine is the major metabolite of released dopamine in the rat frontal cortex: reassessment of the effects of antipsychotics on the dynamics of dopamine release and metabolism in the frontal cortex, nucleus accumbens, and striatum by a simple two pool model. J Neurochem 63:972-979.

Krettek JE, Price JL (1977) The cortical projections of the mediodorsal nucleus and adjacent thalamic nuclei in the rat. J Comp Neurol 171:157-192.

Kuhar MJ, Ritz MC, Boja JW (1991) The dopamine hypothesis of the reinforcing properties of cocaine. Trends Neurosci 14:299-302.

Lee TH, Gee KR, Ellinwood EH, Seidler FJ (1996) Combining "cageddopamine" photolysis with fast-scan cyclic voltammetry to assess dopamine clearance and release autoinhibition in vitro. J Neurosci Methods 67:221-231.

Leranth C, Pickel VM (1989) Electron microscopic pre-embedding double immunostaining methods. In: Neuroanatomical tract tracing 2 (Heimer L, Zaborsky L, eds), pp 129-172. New York: Plenum.

Levey A, Hersch S, Rye D, Sunahara R, Niznik H, Kitt C, Price D, Maggio R, Brann M, Ciliax B (1993) Localization of $D_{1}$ and $D_{2}$ dopamine receptors in brain with subtype-specific antibodies. Proc Natl Acad Sci USA 90:8861-8865.

Lew P, Patel A, Vaughan RA, Wilson A, Kuhar MJ (1992) Microheterogeneity of dopamine transporters in rat striatum and nucleus accumbens. Brain Res 584:266-271.

Lewis DA, Sesack SR (1997) Dopamine systems in the primate brain. In: Handbook of chemical neuroanatomy, the primate nervous system, Pt I (Bloom FE, Björklund A, Hökfelt T, eds), pp 261-373. New York: Elsevier Science.

Lewis DA, Hawrylak VA, Melchitzky DS, Sesack SR (1996) Dopamine terminals in the monkey prefrontal cortex selectively innervate parvalbumin-containing local circuit neurons. Soc Neurosci Abstr 22:1321.

Lindvall O, Björklund A (1984) General organization of cortical monoamine systems. In: Monoamine innervation of cerebral cortex (Descarries L, Reader TR, Jasper HH, eds), pp 9-40. New York: Liss.

Lorang D, Amara SG, Simerly RB (1994) Cell type-specific expression of catecholamine transporters in the rat brain. $J$ Neurosci 14:4903-4914.

Maisonneuve IM, Keller RW, Glick SD (1990) Similar effects of D-amphetamine and cocaine on extracellular dopamine levels in medial prefrontal cortex of rats. Brain Res 535:221-226.

Marshall JF, O'Dell SJ, Navarrete R, Rosenstein AJ (1990) Dopamine high-affinity transport site topography in rat brain: major differences between dorsal and ventral striatum. Neuroscience 37:11-21.

Matthews DE, Farewell VT (1996) Using and understanding medical statistics. Basel: Karger.

Miller GW, Staley JK, Heilman CJ, Perez JT, Mash DC, Rye DB, Levey AI (1997) Immunochemical analysis of dopamine transporter protein in Parkinson's disease. Ann Neurol 41:530-539.

Moghaddam B, Bunney BS (1989) Differential effect of cocaine on extracellular dopamine levels in rat medial prefrontal cortex and nucleus accumbens: comparison to amphetamine. Synapse 4:156-161.

Mrzljak L, Bergson C, Pappy M, Huff R, Levenson R, Goldman-Rakic PS (1996) Localization of dopamine $\mathrm{D}_{4}$ receptors in GABAergic neurons of the primate brain. Nature 381:245-248.

Nicholson C (1995) Interaction between diffusion and MichaelisMenten uptake of dopamine after iontophoresis in striatum. Biophys J 68:1699-1715.

Nirenberg MJ, Vaughan RA, Uhl GR, Kuhar MJ, Pickel VM (1996) The dopamine transporter is localized to dendritic and axonal plasma membranes of nigrostriatal dopaminergic neurons. J Neurosci 16:436-447.

Niznik HB, Fogel EF, Fassos FF, Seeman P (1991) The dopamine transporter is absent in parkinsonian putamen and reduced in caudate nucleus. J Neurochem 56:192-198.

Patel AP, Cerruti C, Vaughan RA, Kuhar MJ (1994) Developmentally regulated glycosylation of dopamine transporter. Dev Brain Res 83:53-58.

Peters A, Palay SL, Webster HD (1991) The fine structure of the nervous system. Neurons and their supporting cells. New York: Oxford. 
Pickel VM, Beckley SC, Joh TH, Reis DJ (1981) Ultrastructural immunocytochemical localization of tyrosine hydroxylase in the neostriatum. Brain Res 225:373-385.

Pozzi L, Invernizzi R, Cervo L, Vallebuona F, Samanin R (1994) Evidence that extracellular concentrations of dopamine are regulated by noradrenergic neurons in the frontal cortex of rats. J Neurochem 63:195-200.

Scatton B, Dubois A, Dubocovich ML, Zahniser NR, Fage D (1985) Quantitative autoradiography of ${ }^{3} \mathrm{H}$-nomifensine binding sites in rat brain. Life Sci 36:815-822.

Séguéla P, Watkins KC, Descarries L (1988) Ultrastructural features of dopamine axon terminals in the anteromedial and the suprarhinal cortex of adult rat. Brain Res 442:11-22.

Sesack SR, Aoki C, Pickel VM (1994) Ultrastructural localization of $\mathrm{D}_{2}$ receptor-like immunoreactivity in midbrain dopamine neurons and their striatal targets. J Neurosci 14:88-106.

Sesack SR, Snyder CL, Lewis DA (1995) Axon terminals immunolabeled for dopamine or tyrosine hydroxylase synapse on GABAimmunoreactive dendrites in rat and monkey cortex. J Comp Neurol 363:264-280.

Sesack SR, Hawrylak VA, Guido MA, Melchitzky DS, Lewis DA, Levey AI (1996) Dopamine axon varicosities in the prefrontal cortex lack immunoreactivity for the dopamine transporter. Soc Neurosci Abstr 22:1786.

Sharp T, Zetterström T, Ungerstedt U (1986) An in vivo study of dopamine release and metabolism in rat brain regions using intracerebral dialysis. J Neurochem 47:113-122.

Shimada S, Kitayama S, Walther D, Uhl G (1992) Dopamine transporter mRNA: dense expression in ventral midbrain neurons. Mol Brain Res 13:359-362.
Simon H, Scatton B, Le Moal M (1980) Dopaminergic A10 neurones are involved in cognitive functions. Nature 286:150-151.

Smiley JF, Goldman-Rakic PS (1993) Heterogeneous targets of dopamine synapses in monkey prefrontal cortex demonstrated by serial section electron microscopy: a laminar analysis using the silverenhanced diaminobenzidine sulfide (SEDS) immunolabeling technique. Cereb Cortex 3:223-238.

Smith SJ, Augustine GJ (1988) Calcium ions, active zones, and synaptic transmitter release. Trends Neurosci 11:458-464.

Swanson LW (1982) The projections of the ventral tegmental area and adjacent regions: a combined fluorescent retrograde tracer and immunofluorescence study in the rat. Brain Res Bull 9:321-353.

Tanda G, Carboni E, Frau R, Di Chiara G (1994) Increase of extracellular dopamine in the prefrontal cortex: a trait of drugs with antidepressant potential? Psychopharmacology 115:285-288.

Uhl GR (1992) Neurotransmitter transporters (plus): a promising new gene family. Trends Neurosci 15:265-268.

Van Eden CG, Hoorneman EMD, Buijs RM, Matthijssen MAH, Geffard M, Uylings HBM (1987) Immunocytochemical localization of dopamine in the prefrontal cortex of the rat at the light and electron microscopic level. Neuroscience 22:849-862.

Vaughan RA, Brown VL, McCoy MT, Kuhar MJ (1996) Species- and brain region-specific dopamine transporters: immunological and glycosylation characteristics. J Neurochem 66:2146-2152.

White FJ, Wang RY (1984) A10 dopamine neurons: role of autoreceptors in determining firing rate and sensitivity to dopamine agonists. Life Sci 34:1161-1170.

Wolf ME, Galloway MP, Roth RH (1986) Regulation of dopamine synthesis in the medial prefrontal cortex: studies in brain slices. J Pharmacol Exp Ther 236:699-707. 